\title{
O4 - COMPORTAMENTO MINERAL DOS TERMOFOSFATOS DE ALUMÍNIO COM ADIÇÃO DE ESCÓRIA EM 700 e $1100{ }^{\circ} \mathrm{C}$
}

http://gmga.com.br/04-comportamento-mineral-dos-termofosfatos-de-aluminio-com-adicao-de-escoriaem-700-e-1100-cl

dc

\subsection{9/ISSN.2594-942X.v52018i1a4MSCS}

SOUSA, Maria Silvia Camarão ${ }^{1}$; CHOQUE FERNANDEZ, Oscar Jesus ${ }^{2}$; BRASIL, Edilson ${ }^{3}$; COSTA, Marcondes Lima da ${ }^{4}$

${ }^{1}$ Instituto Federal do Pará, IFPA-Campus Belém, Graduada Engenharia de Materiais, msilviacamarao@gmail.com

${ }^{2}$ Instituto Federal do Pará, IFPA-Campus Belém, Prof. Dr. Curso Técnico em Metalurgia/Engenharia de Materiais, oscar.fernandez@ifpa.edu.br

${ }^{3}$ Empresa Brasileira de Pesquisa Agropecuária, Dr. Embrapa, edilson.brasil@embrapa.br

${ }^{4}$ Universidade Federal do Pará, UFPA, Prof. Dr. Instituto de Geociências, Programa de Pós-Graduação

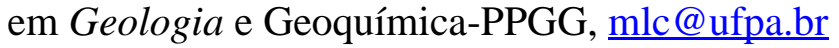

\begin{abstract}
Thermophosphate consists of the thermal treatment of the rock, with or without addition of other materials, being an excellent source of phosphate fertilizer, presenting other nutrients and beneficial elements such as Mg and Si. In this work were used Al-phosphates from Sapucaia (Bonito, State of Pará) and slag of the blast furnace (Marabá, State of Pará), in the ratio 80/20, being subjected to calcination at $700{ }^{\circ} \mathrm{C}$ and $1100{ }^{\circ} \mathrm{C}$ with the objective of verifying the behavior of crystalline phases in these temperatures. The samples were calcined and then characterized by X-ray diffraction (XRD). These analyzes showed that the phosphate ore consists of phases of the crandallite group and quartz and the slag by amorphous material. After calcination at $700^{\circ} \mathrm{C}$, the phases of the thermophosphate and slagthermophosphate are restructured tending to amorphous, except quartz. At this temperature, the solubility of the phosphate material favors the increase in $\mathrm{P}_{2} \mathrm{O}_{5}$ content. At $1100^{\circ} \mathrm{C}$ the identified crystalline phases were: aluminum oxide, aluminum and iron phosphates, calcium and iron phosphates, and silicon oxide. Studies evaluating these materials in agriculture may determine their agronomic efficiency.
\end{abstract}

Keywords: crandallite, calcination, fertilizer 


\section{INTRODUÇÃO}

Os termofosfatos são fertilizantes que utilizam processos de tratamento térmico para favorecer a solubilidade do fósforo contido nas rochas fosfáticas, colocando-o em uma forma mais disponível para os vegetais (Carvalho et al. 2003). A produção de termofosfatos consiste no tratamento térmico da rocha, com ou sem adição de outros materiais. Os termofosfatos são excelentes fontes de fertilizante fosfatado e apresentam também outros nutrientes e elementos benéficos como o Mg e o Si (AGEITEC 2015).

Com o avanço da atividade agropecuária, os solos na Amazônia estão sendo intensamente utilizados, e apesar de apresentarem elevado potencial de utilização para a agricultura, de modo geral, apresentam elevada acidez, elevados teores de Al trocável e deficiência de nutrientes, como Ca, $\mathrm{Mg}$ e P (Nolla et al., 2013). A utilização de alguns resíduos siderúrgicos tem-se mostrado como alternativa viável para o aproveitamento na agricutura, destacando-se as escórias (Amaral 1994 apud Nolla et al. 2013).

\section{Fosfatos de alumínio}

A região nordeste do Pará e noroeste do Maranhão caracterizam-se geologicamente por inúmeros depósitos de fosfatos de alumínio associados a corpos lateríticos maturos, que hoje sustentam os relevos do tipo platô (serra do Pirocaua, serra do Piriá, serra do Cansa Perna), morrotes (Jandiá, Bonito, etc.) e ainda algumas ilhas na região costeira paraense (Itacupim, Peito de Moça e Pedra Grande do Gurupi) e maranhense (ilha de Trauira e Tralhoto) (Costa e Sá 1980, Costa 1991).

Os fosfatos de alumínio constituem um horizonte situado, caracteristicamente, no topo dos perfis lateríticos, logo abaixo da crosta ferruginosa. Esses fosfatos estão representados principalmente por crandalita-goyazita $\left[\mathrm{CaAl}_{3}\left(\mathrm{PO}_{4}\right)_{2}(\mathrm{OH})_{5} \cdot \mathrm{H}_{2} \mathrm{O}\right]-\left[\mathrm{SrAl}_{3}\left(\mathrm{PO}_{4}\right)_{2}(\mathrm{OH})_{5} \cdot \mathrm{H}_{2} \mathrm{O}\right]$, wardita $\left[\mathrm{NaAl}_{3}\left(\mathrm{PO}_{4}\right)_{2}(\mathrm{OH})_{4 \cdot 2} \mathrm{H}_{2} \mathrm{O}\right]$, senegalita $\left[\mathrm{Al}_{2}\left(\mathrm{PO}_{4}\right)(\mathrm{OH})_{3} \cdot \mathrm{H}_{2} \mathrm{O}\right]$, variscita $\left(\mathrm{AlPO}_{4} \cdot 2 \mathrm{H}_{2} \mathrm{O}\right)$, augelita $\left[\mathrm{Al}_{2}\left(\mathrm{PO}_{4}\right)(\mathrm{OH})_{3}\right]$ e outros fosfatos mais raros (Costa e Sá 1980, Schwab et al. 1989).

\section{Escória de Alto-forno}

Na produção do ferro gusa usando alto-forno são geradas escórias (Chiaverini 1986), como resultado da combinação dos elementos constituintes do calcário, com a ganga do minério e as cinzas do carvão. Sua composição varia igualmente dentro de determinados intervalos, como segue:

$\mathrm{SiO}_{2} \quad-\quad 29$ a $38 \%$

$\mathrm{Al}_{2} \mathrm{O}_{3} \quad-\quad 10$ a $22 \%$

$\mathrm{CaO}+\mathrm{MgO} \quad-\quad 44 \mathrm{a} 48 \%$ 
$\mathrm{FeO}+\mathrm{MnO} \quad-\quad 1$ a $3 \%$

$\mathrm{CaS} \quad-\quad 3$ a $4 \%$

O presente trabalho originou-se de uma demanda da Empresa Brasileira de Pesquisa Agropecuária (EMBRAPA) que solicitou um estudo de caracterização de termofosfatos, obtido a partir da mistura de rocha fosfatada de alumínio com adição de escória de siderurgia, visando obter informações sobre a eficiência agronômica do termofosfato de alumínio como fonte de P. Com esse fim, a EMBRAPA forneceu amostras de fosfatos de alumínio provenientes do depósito mineral de Sapucaia (município de Bonito/PA) e escórias da usina de ferro-gusa de Marabá/PA.

\section{MATERIAIS E MÉTODOS}

\section{Materiais}

Para o desenvolvimento desde trabalho utilizou-se amostras de fosfatos de alumínio e de escória de alto forno. As matérias primas foram fornecidas pela EMBRAPA, finamente moídas em granulometria passante em peneira de $150 \mu \mathrm{m}$ (100 mesh). Os fosfatos de alumínio procedem do depósito mineral de Sapucaia (Bonito/PA) e as escórias da usina Siderúrgica Norte Brasil S.A. (SINOBRAS) de Marabá/PA.

\section{Métodos}

A primeira etapa do trabalho consistiu no procedimento de homogeneização do fosfato de alumínio com a escória, na proporção de $80 \%$ de fosfato de alumínio para $20 \%$ de escória. (Figura 1 e 2).

Na sequência, as amostras foram submetidas à secagem a $110^{\circ} \mathrm{C}$ por 1 hora e em seguida, ao processo de calcinação nas temperaturas de 700 e $1100^{\circ} \mathrm{C}$. Os equipamentos utilizados para a secagem e calcinação foram estufa com circulação de ar SL-102 e o forno mufla da marca JUNG modelo LF9613 (Figura 3), respectivamente. 


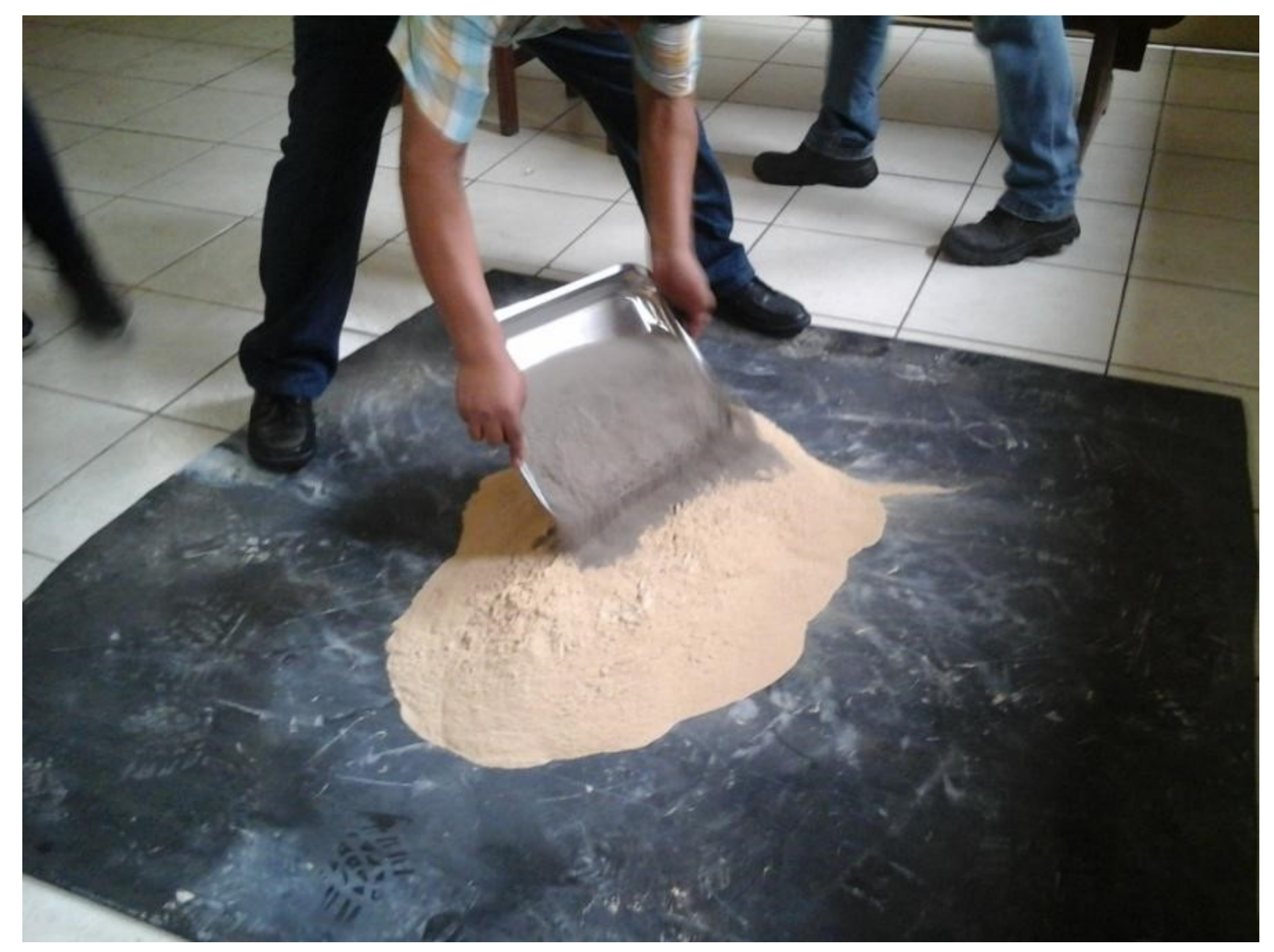

Figura 1. Homogeneização da mistura do fosfato de alumínio com a adição de escória. 


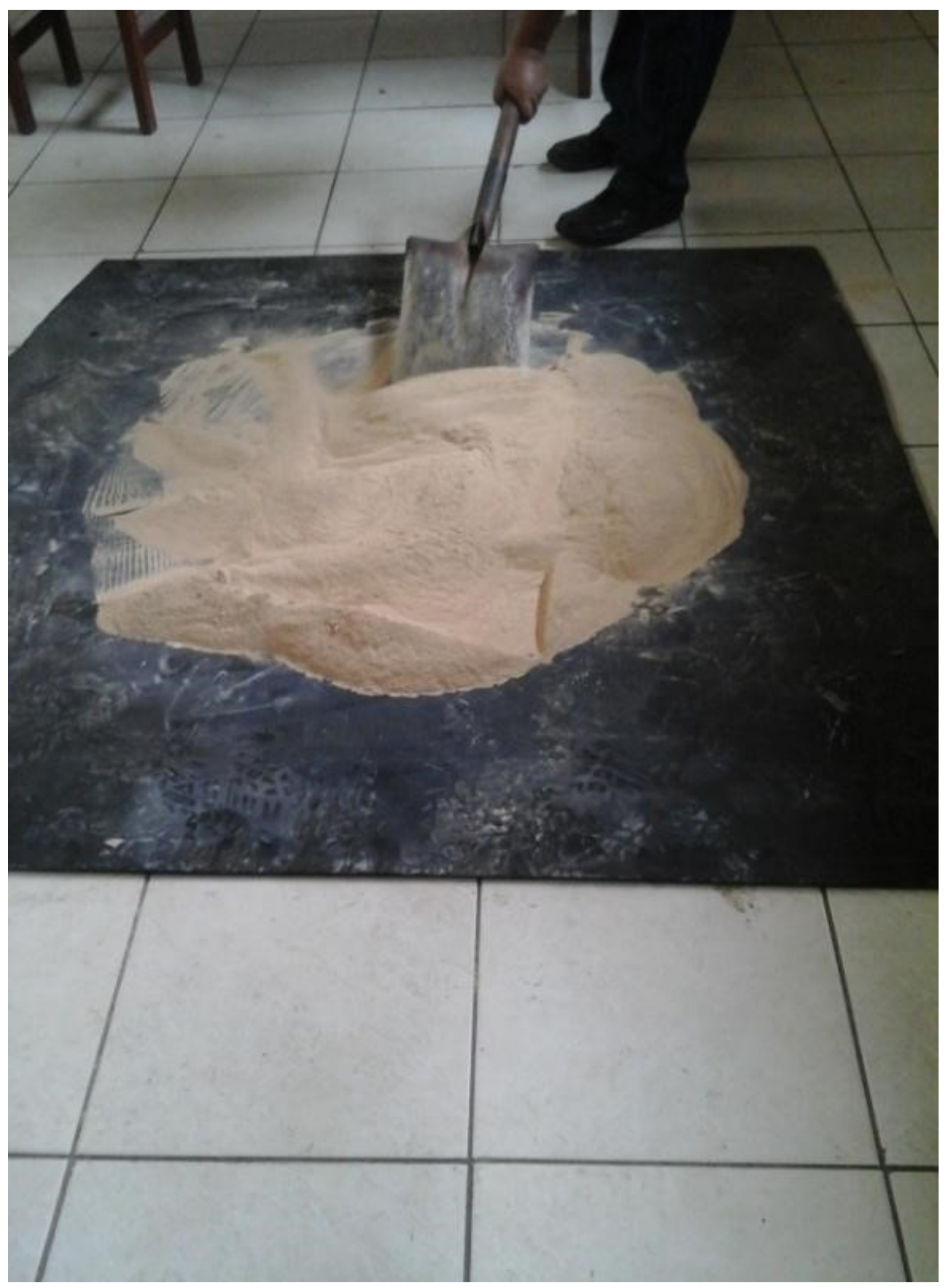

2. Homogeneização da mistura do fosfato de alumínio com a adição de escória. 
04 - COMPORTAMENTO MINERAL DOS TERMOFOSFATOS DE ALUMÍNIO COM ADIÇÃO DE ESCÓRIA EN GMGA - Grupo de Mineralogia e Geoquímica Aplicada - http://gmga.com.br

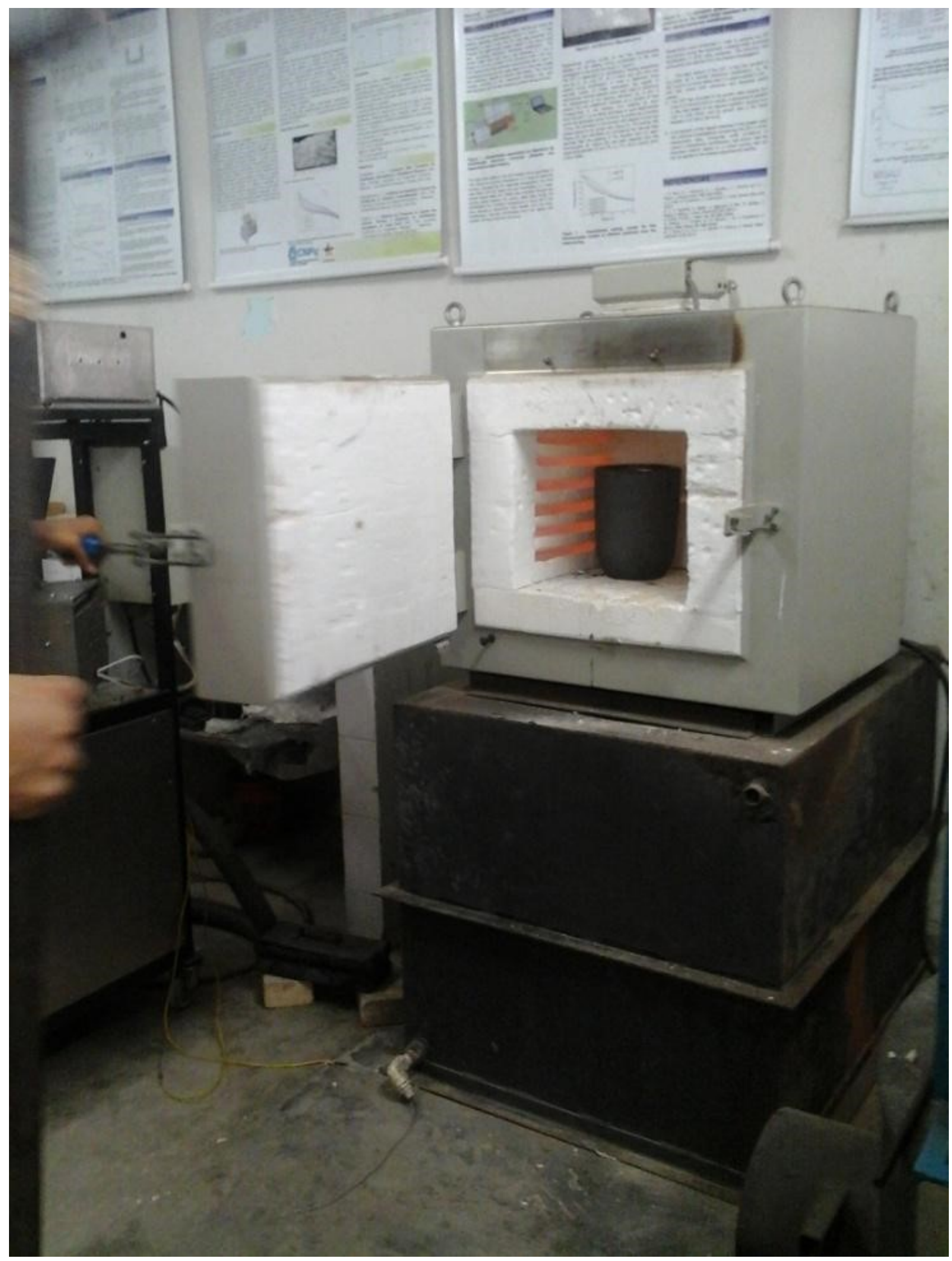


Figura 3. Calcinação de amostra em forno mufla JUNG modelo LF9613.

Para caracterização, as amostras foram cominuídas em gral de ágata, preparadas e levadas para análises no difratômetro Phillips PW1050, com tubo de $\mathrm{Cu}(?=1,5406 \AA)$. Os arquivos digitais gerados foram interpretados através dos softwares $X^{\prime}$ PERT PRO MPD da PANalytical e a base de dados de minerais PDF (Powder Diffraction Data) do International Centre for Diffraction Data (ICDD).

\section{RESULTADOS E DISCUSSÕES}

Além das amostras submetidas à calcinação, as amostras de escória e do fosfato (sem adição de escória) também foram submetidas à análise difratométrica, visando à identificação dos minerais presentes antes de serem submetidos ao tratamento térmico. Os resultados mostraram que a escória está constituída, basicamente, por material amorfo (Figura 4), e que o minério fosfático está constituído por quartzo $\left(\mathrm{SiO}_{2}\right)$, crandallita $\left[\mathrm{CaAl}_{3}\left(\mathrm{PO}_{4}\right)_{2}(\mathrm{OH})_{5} \mathrm{H}_{2} \mathrm{O}\right]$ e por vezes foi identificado woodhouseita $\left[\mathrm{CaAl}_{3}\left(\mathrm{PO}_{4}\right)\left(\mathrm{SO}_{4}\right)(\mathrm{OH})_{6}\right]$ (Figura 5).

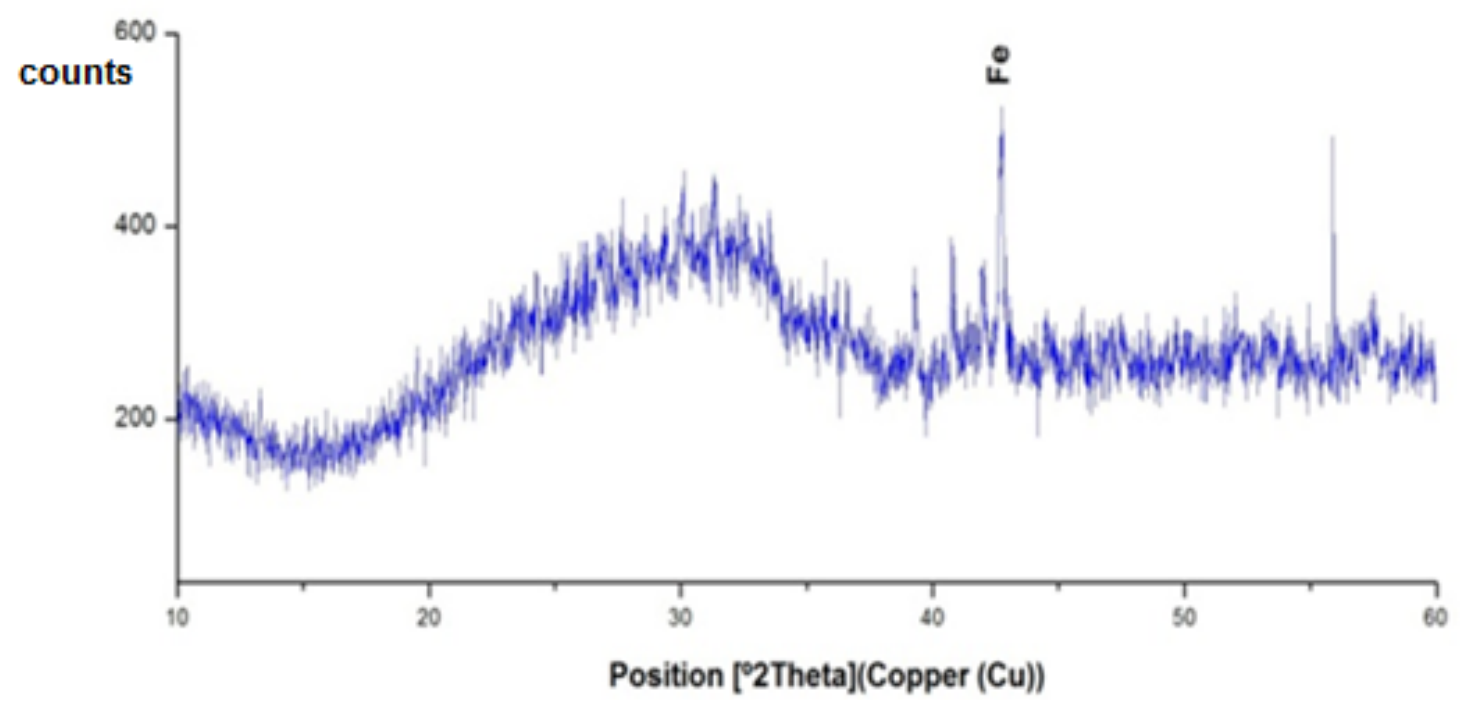

Figura 4. Espectro

difratométrico do material escória (Fe: ferro). 


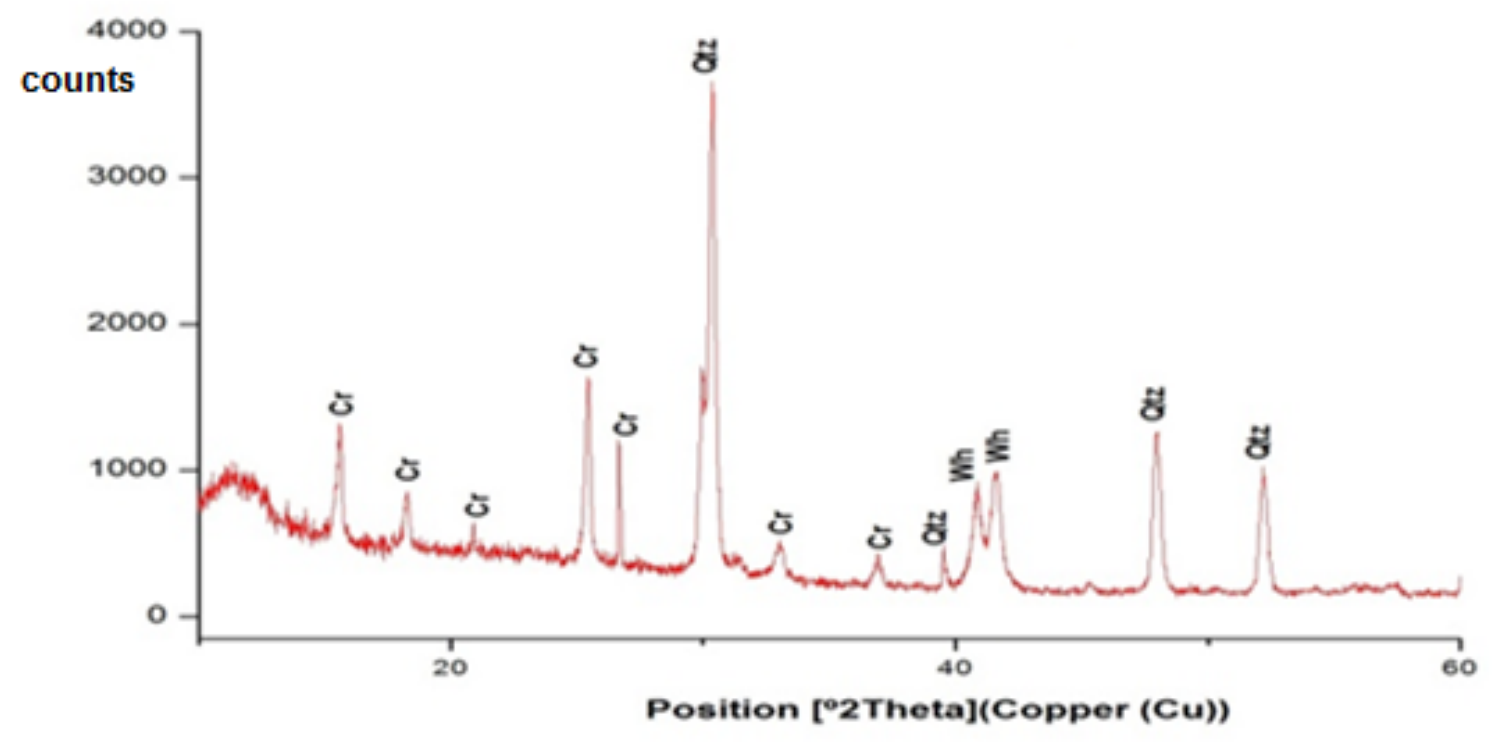

Figura 5.

Espectro difratométrico da amostra do fosfato de alumínio (Cr: crandallita; Qtz: quartzo; Wh: woodhouseita).

Após a calcinação a $700^{\circ} \mathrm{C}$, tanto do termofosfato sem adição de escória quanto do termofosfato com adição de escória, mostram que o material ocorre desestruturado, predominantemente amorfo, mas ainda contendo quartzo $\left(\mathrm{SiO}_{2}\right)$ (Figuras 6 e 7).

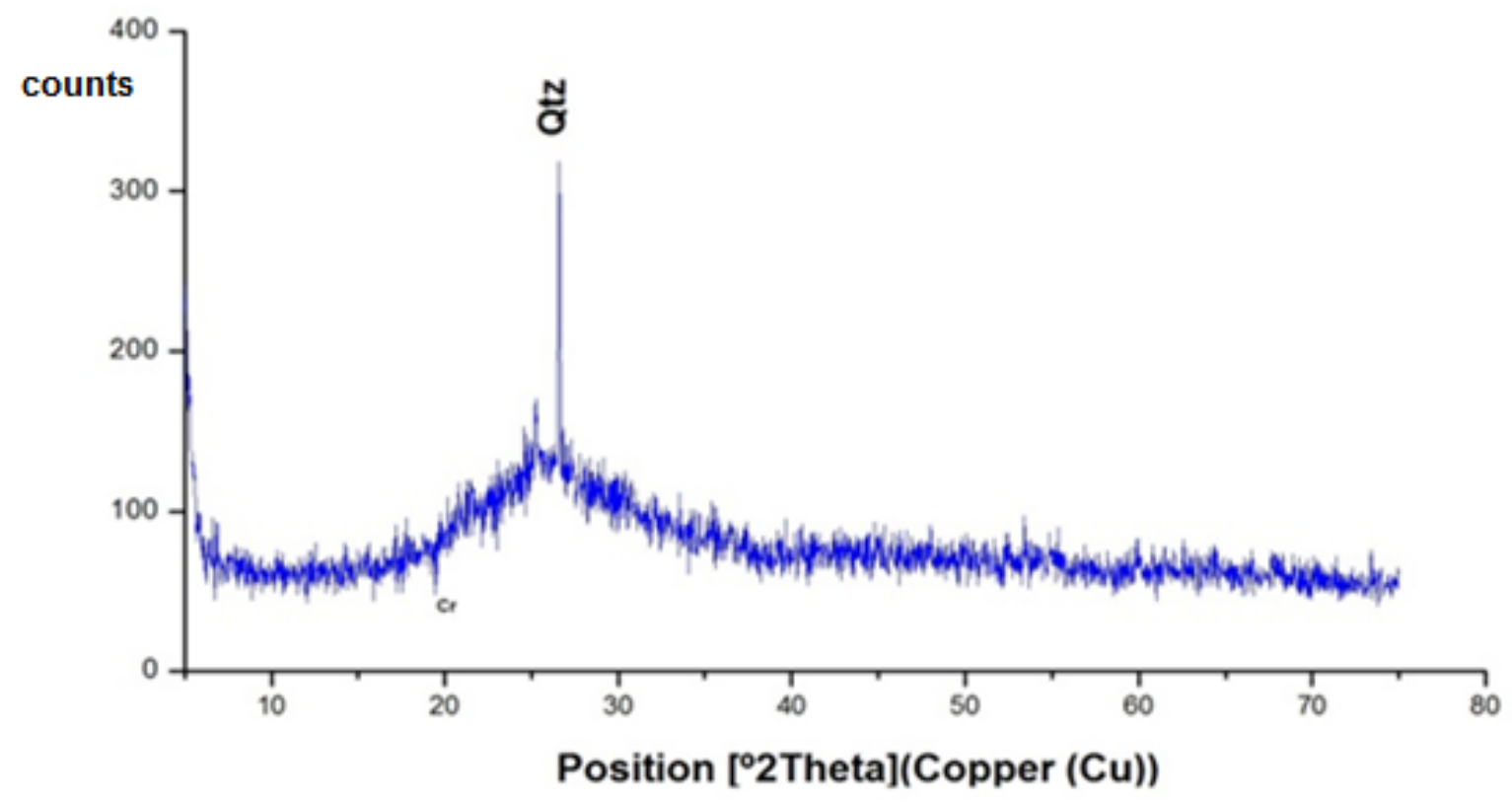

Figura 6.

Espectro difratométrico do termofosfato de alumínio sem adição de escória, calcinado a $700^{\circ} \mathrm{C}$. (Qz: quartzo). 


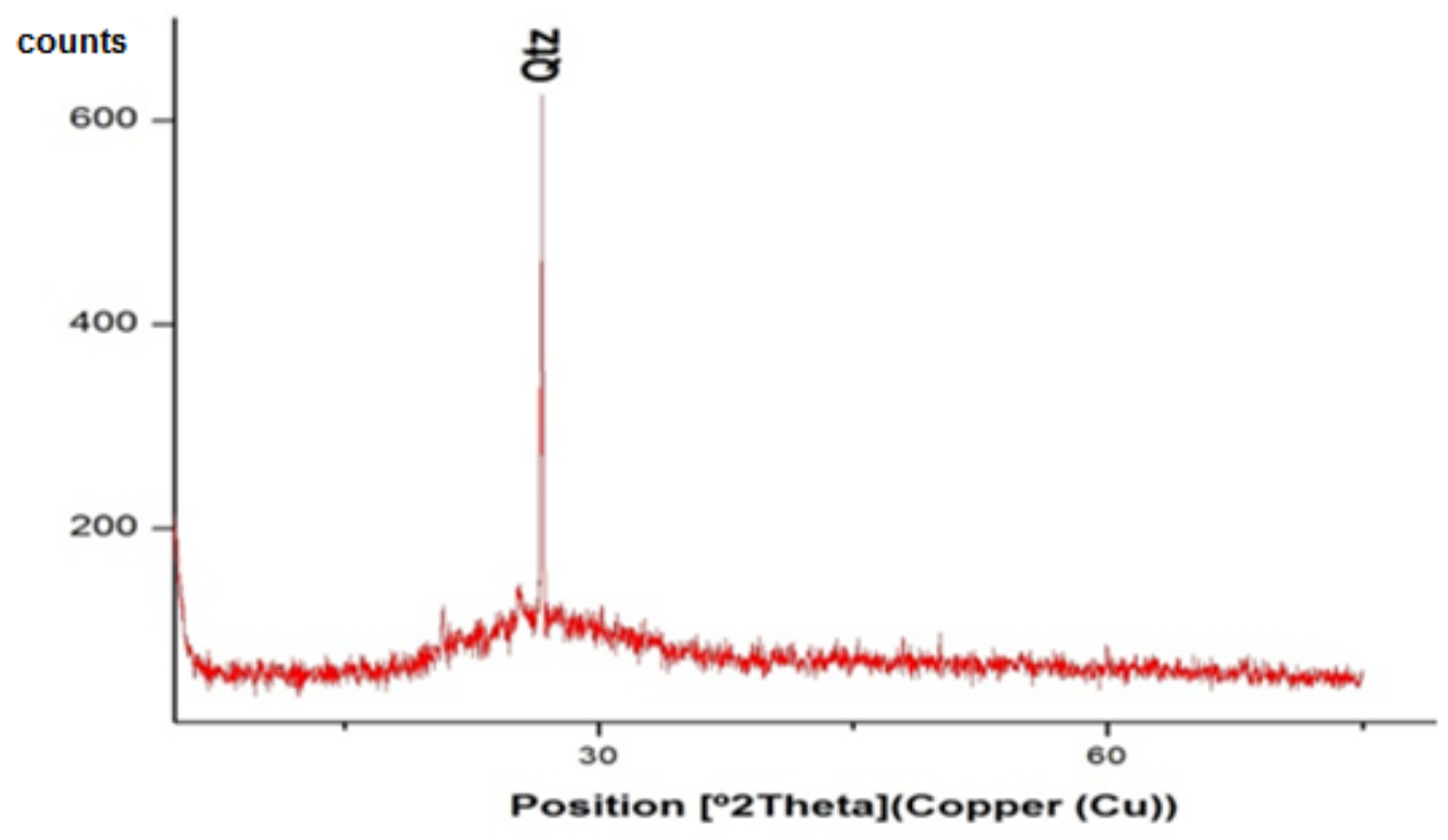

Figura 7.

Espectro difratométrico do termofosfato de alumínio com a adição de escória, calcinado a $700{ }^{\circ} \mathrm{C}$. (Qz: quartzo).

Quando as amostras de fosfato de alumínio sem adição de escória e com inclusão de escória foram calcinadas a $1100^{\circ} \mathrm{C}$, as fases recristalizam apresentando outras fases novas como fosfatos de alumínio e ferro $\left(\mathrm{Al}_{0.67} \mathrm{Fe}_{0.35} \mathrm{PO}_{4}\right)$ e fosfatos de cálcio e ferro $\left(\mathrm{Ca}_{9} \mathrm{FePO}{ }_{4}\right)$. Quartzo $\left(\mathrm{SiO}_{2}\right)$ também permanece nesta temperatura. A fase fosfatos de alumínio $\left(\mathrm{AlPO}_{4}\right)$ foi identificada exclusivamente na amostra de termofosfato sem adição de escória (Figuras 8 e 9). 


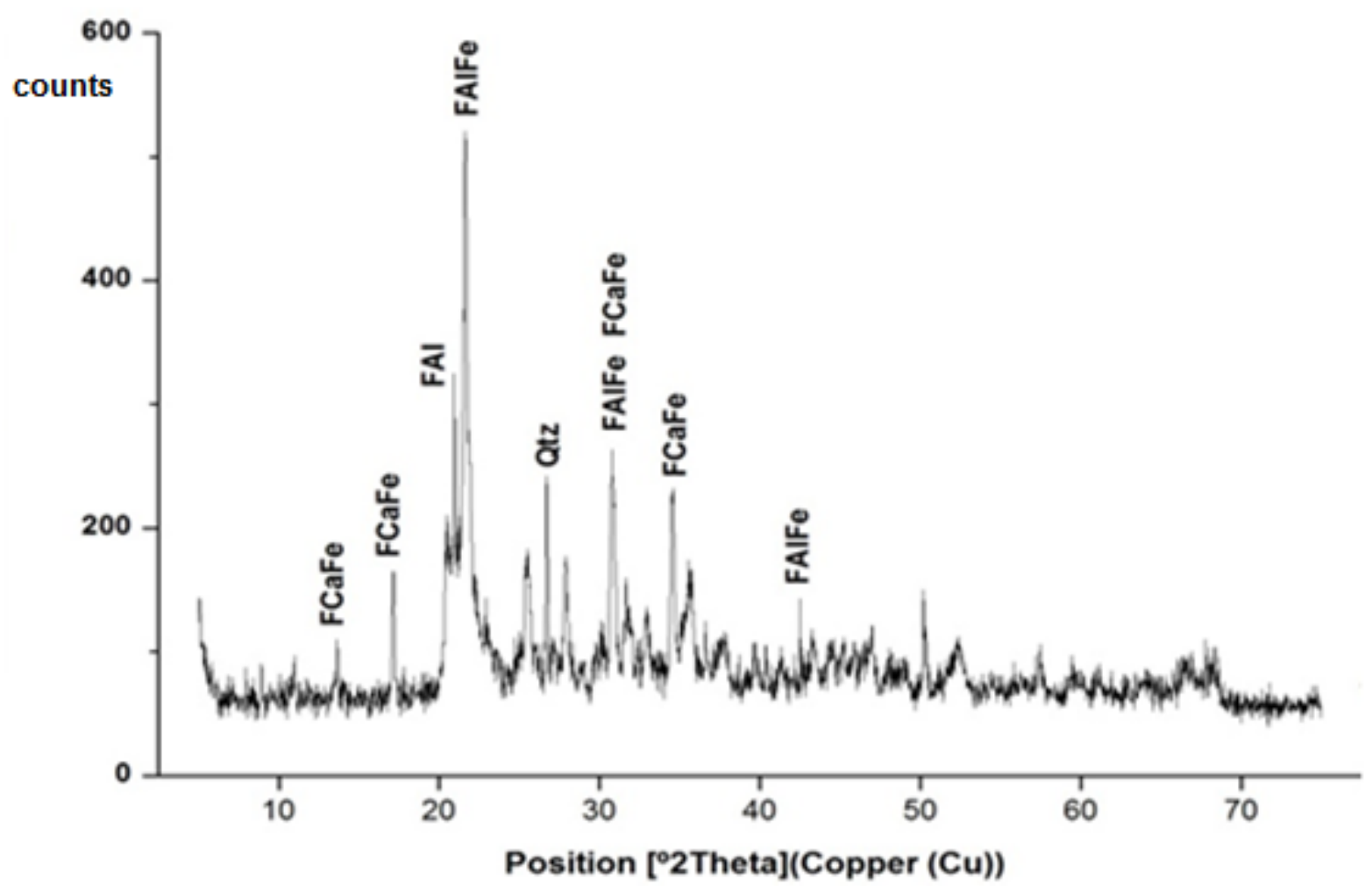

Figura 8.

Espectro difratométrico do termofosfato de alumínio sem adição de escória após calcinação a $1100^{\circ} \mathrm{C}$ (FAl: Fosfato de alumínio; FAlFe: Fosfato de alumínio e ferro; FCaFe : Fosfato de cálcio e ferro; Qtz: quartzo).

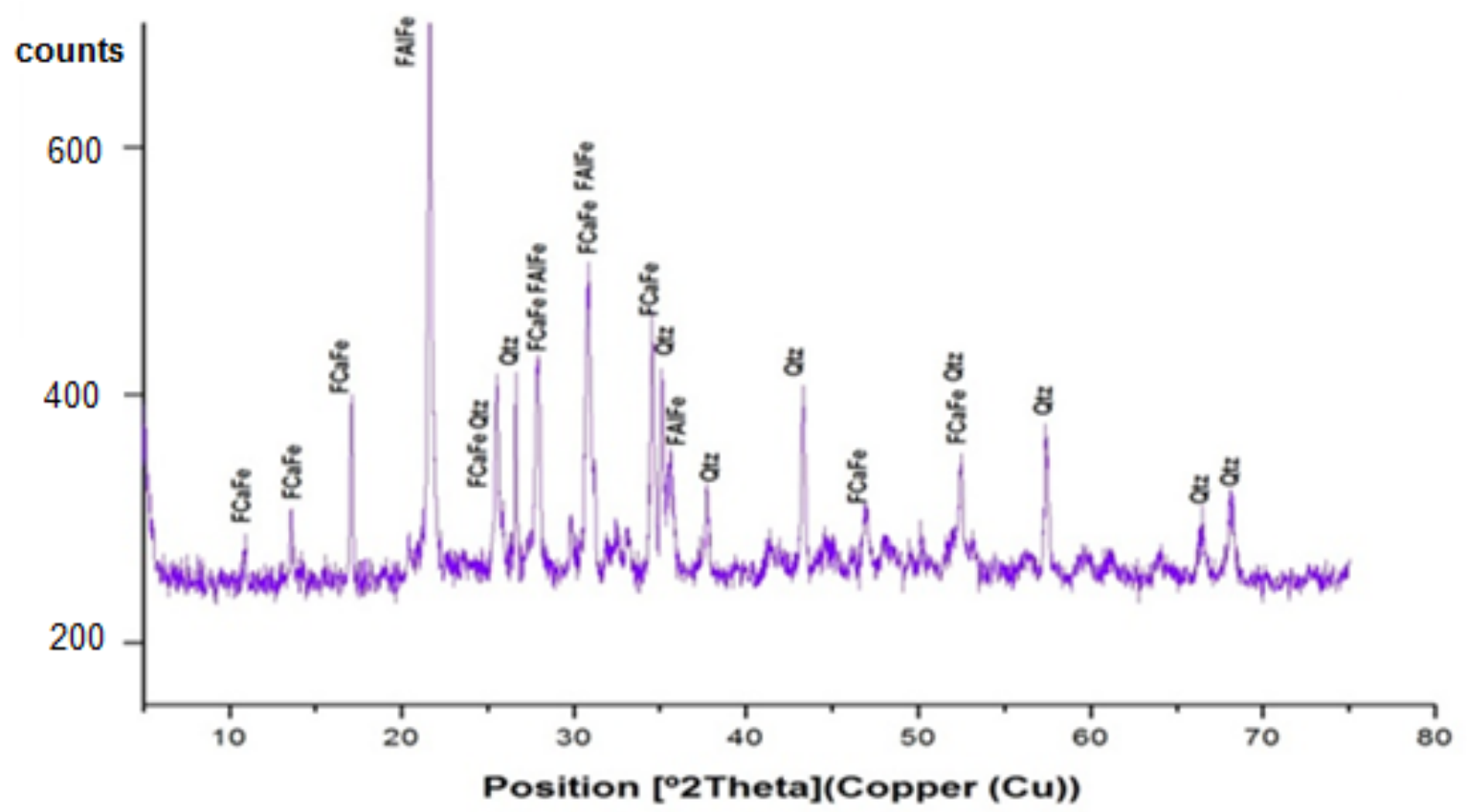

Figura 9.

Espectro difratométrico do termofosfato de alumínio com a adição de escória, após calcinação a $1100^{\circ} \mathrm{C}$ 
(FAlFe: Fosfato de alumínio e ferro; FCaFe : Fosfato de cálcio e ferro; Qtz: quartzo).

\section{CONCLUSÕES}

A caracterização dos materiais o minério fosfático mostra que o principal mineral fosfatado é a crandallita, associado com outras fases fosfatadas (traços) e quartzo e que, a escória apresenta substâncias amorfas;

Os termofosfatos sem e com a adição de escória na temperatura de $700^{\circ} \mathrm{C}$ mostraram fases amorfas, provavelmente soluveis, inferindo-se que o $\mathrm{P}_{2} \mathrm{O}_{5}$ é reativo e biodisponível;

Novas estruturas cristalinas são formadas a temperatura de $1100^{\circ} \mathrm{C}$. Os padrões de termofosfatos sem e com inclusão de escória, apresentam fases como fosfatos de alumínio, fosfatos de alumínio e ferro, fosfatos de cálcio e ferro e, quartzo.

A utilização de escória siderúrgica na produção de termofosfatos como fertilizante corretivo de acidez dos solos pode representar uma importante alternativa para o aproveitamento de materias primas locais, em regiões do Brasil com pouco acesso aos fertilizantes fosfatados tradicionais.

\section{REFERÊNCIAS}

AGEITEC - Agência Embrapa de Informação Tecnológica. Árvore do Conhecimento - Cana-de-açucar. Adubação Mineral. 2015. Disponível em: https://www.agencia.cnptia.embrapa.br/gestor/cana-deacucar/arvore/CONTAG01_38_711200516717.html. Acesso em: 20 out. 2016.

Brasil, E. C., Cekinski, E., Santos, D., Dantas, R., Hungria, L. 2015. Eficiência agronômica de termofosfato de alumínio obtido a partir da mistura de fosfato de alumínio e escória de siderurgia. Congresso Brasileiro de Ciência do Solo, 35. Natal, RN.

Chiaverini, V. 1986. Tecnologia Mecânica. Vol.II. 2ª edição, Editora McGraw-Hill; 1986.

Carvalho, C.E.; Galvão, L.C.R.; Reis, L.B.; Udaeta, M.E.M. 2003. Avaliação completa dos recursos para produção de termofosfato: uma aplicação do PIR. Anais 3. Enc. Energ. Meio Rural.

Costa, M.L. da; Sá, J.H.S. Os fosfatos lateríticos da Amazônia Oriental: geologia, mineralogia, geoquímica e correlação com as bauxitas da Amazônia. In: CONGR. BRAS. GEOL., 31, 1980. Santa Catarina. Anais... Santa Catarina: SBG, 1980. v. 3, p.1459-72

Costa, M. L.; Castro, C. De; Silva, G. R. da. A Viabilidade de Termofosfatos a partir de Matérias-Primas de Maicuru e sua Importância para o Desenvolvimento Mineral e Agronomico da Amazonia. Anais do III Simpósio de Geologia da Amazônia. Belém, Pará. 1991. 
Costa, M.L., Choque Fernandez, O.J., Toledo, M.C., Passos, C., Freitas, P. 2004. A turquesa de Itacupim, Pará. Revista da Escola de Minas de Ouro Preto. 57:261-266.

Leite, A. S. 2014. Geologia, Mineralogia e Geoquímica dos fosfatos de Sapucaia (Bonito-PA). MS Dissertação Mestrado, UFPA. Belém/PA.

Nolla, A.; Korndörfer, G.H.; Ramos, L.A.; Silva T.R.B.; Silva, M.A.G. 2013. Potencialidade de reação de corretivos, fertilizantes e do gesso agrícola em um latossolo vermelho distroférrico típico. Journal of Agronomic Sciences, Umuarama, 2(1):136-143.

Schwab, R.G., Herold, H. Costa, M.L., Oliveira, N.P. 1989. The formation of aluminous phosphates trhough lateritic weathering. In: Products and deposits. Theophastrus Publications, Alhen, 2:369-386.

PDF generated by Kalin's PDF Creation Station 